\title{
Results of a survey about specific inflammatory bowel disease units in Andalusia
}

\author{
J. M. Herrerías Gutiérrez, F. Argüelles Arias, M. Moreno Gallego ${ }^{1}$, J. de Dios Vega² ${ }^{2}$ R. Martín-Vivaldi \\ Martínez ${ }^{3}$, A. Domínguez Macías ${ }^{4}$, A. M. Sánchez Cantos ${ }^{5}$, A. Ferré Álamo ${ }^{6}$, R. Manteca ${ }^{7}$, \\ J. L. Vega Sáenz ${ }^{8}$, M. Romero Gómez ${ }^{9}$ and J. L. Márquez Galán ${ }^{10}$
}

Service of Digestive Diseases. Virgen Macarena Hospital. Sevilla, Spain. ${ }^{~}$ Puerta del Mar Hospital. Cádiz, Spain. ${ }^{2}$ Reina Sofía Hospital. Córdoba, Spain. ${ }^{3}$ Virgen de las Nieves Hospital. Granada, Spain. ${ }^{4} J u a n$ Ramón Jiménez Hospital. Huelva, Spain. ${ }^{5}$ Costa del Sol Hospital. Marbella, Málaga. Spain. ${ }^{6}$ Hospital de Jerez. Cádiz, Spain. ${ }^{7}$ Carlos Haya Regional Hospital. Málaga, Spain. ${ }^{8}$ Torrecárdenas Hospital. Almería, Spain. ${ }^{9}$ Nuestra Señora de Valme Hospital. Sevilla, Spain. ${ }^{10}$ Virgen del Rocío University Hospital. Sevilla, Spain. Andalusian Team of Chiefs of Gastroenterology Units and Departments

\begin{abstract}
Background: inflammatory bowel disease (IBD) has become one of the most prevalent pathologies in Gastroenterology Units, which added to its clinical outcome, treatment, the complexity of affected patients and the need to be continuously updated for the correct management of the disease, have made essential the presence of specific IBD units in each hospital.

Objectives: the primary aims of this study were: a) to reveal the existence of these units in our area and how they work; and b) to draw conclusions regarding the necessary resources in these units and their aims.

Material and methods: In order to analyse the presence of these specialized units and the available resources in Andalusian hospitals, a 24-question survey was designed, being answered by 11 hospitals. The evaluated questions included the number of days patients are attended and the number of physicians attending the unit, the number of available healthcare assistants, if emergencies are attended or not, if there is an activated telephone number for patient consultation, if a day care unit is available and if new treatments are easily accessible.

Results: a specific IBD unit is present in all studied hospitals attending more than 11 patients each, although in the $63.4 \%$ of the cases patients are not attended more than 3 days per week. On the other hand, the $81.8 \%$ of the included hospitals attend emergencies although only the $54.5 \%$ of them had a specific telephone number for patient attendance.

Conclusions: a specific IBD unit is present in many Andalusian hospitals, although some deficiencies can be observed. The general opinion of this Group is that these units are necessary in order to properly attend, monitorize and treat patients affected by IBD.
\end{abstract}

Received: 09-01-09.

Accepted: 13-01-09.

Correspondence: Juan Manuel Herrerías Gutiérrez. Servicio de Aparato Digestivo. Hospital Universitario Virgen Macarena. Avda. Doctor Fedriani, s/n.41071 Sevilla, Spain.e-mail: jmhg@us.es
Key words: Inflammatory bowel disease. IBD Unit. Croh's disease. Ulcerative colitis.

Herrerías Gutiérrez JM, Argüelles Arias F, Moreno Gallego M, De Dios Vega J, Martín-Vivaldi Martínez R, Domínguez Macías A, Sánchez Cantos AM, Ferré Álamo A, Manteca R, Vega Sáenz JL, Romero Gómez M, Márquez Galán JL. Results of a survey about specific inflammatory bowel disease units in Andalusia. Rev Esp Enferm Dig 2009; 101: 187-194.

\section{INTRODUCTION}

Inflammatory bowel disease (IBD) has emerged as one the most prevalent in Gastroenterlogy Units. Therefore, and despite being only two causal entities, clinical outcome, treatment and the complexity of affected patients have made a specific IBD unit essential in many hospitals. It is estimated that prevalence rates in Northern Europe and North America varies between 100 and 200 cases per 100,000 people (1-4). In Spain, the incidence of ulcerative colitis (UC) varies from 0,6 to 8 cases per 100,000 people and year and Crohn's disease (CD) varies from 0.4 to 5.5 cases per 100,000 people and year (5) and, according to Saro et al., the prevalence of IBD in Asturias is 16.55 being 9.52 for UC and 5.95 for CD (6). In Andalusia, there are no published data concerning IBD prevalence, although there is a study carried out in Huelva in which IBD incidence was estimated to be 5.2 per 100,000 people and year for UC and 6.6 cases for CD per 100,000 people and year (7). Accord- 
ing to IBD's white paper (8) the prospects for 2010 announce more than 800,000 new cases of IBD, counting for more than 118,000 patients.

On the other hand, the costs derived from each IBD patient can be reduced throughout these units due to a lower number of visits to the Emergency Room (ER) and, therefore, the number of admissions to hospital. A specific unit reduces direct costs of the disease, especially those derived from hospital admissions, and indirect costs, related to patients not attending their jobs, being cost-effective (9).

Furthermore, the introduction of biological treatments and a broad range of new therapeutic tools, as well as potential complications of the disease, not only digestive but also extraintestinal, increase the need of creating or having units exclusively dedicated to this pathology. Finally, there is an increasing demand of personalized attention by patients, with an appropriate doctor-patient relationship, and offering the possibility of "on demand" consultations, in order to avoid attending ERs. Nevertheless, these units have not been created in many Gastroenterology Units due to a lack of infrastructure. Following previous publications $(10,11)$, one of the purposes of this survey was to study these units in Andalusia.

\section{OBJECTIVES}

The primary aims of this study were:

- To reveal the existence of these units in our area and how they work.

- To draw conclusions regarding the necessary resources in these units and their aims.

\section{MATERIAL AND METHODS}

A survey regarding IBD units was designed, and a descriptive analysis of answers submitted by 11 Andalusian hospitals - H.U. "Virgen de Valme", "Virgen del Rocío", and "Virgen Macarena" in Seville; H. SAS Jerez and "Puerta del Mar" in Cádiz; H. Costa del Sol (Marbella) and H.U. "Carlos Haya" in Málaga; H.U. "Virgen de las Nieves" in Granada; H. "Juan Ramón Jiménez" in Huelva; H.U. "Reina Sofía" in Córdoba, and H. "Torrecárdenas" in Almería - was carried out. The survey consisted of 24 questions with one possible answer out of several options in order to assess not only the units' current status but also their ideal conditions.

\section{Survey}

\section{Questions}

1. How many users does your unit cover? Fewer than 100,000 people; between 100,000 and 250,000 people; between 250,000 and 400,000 people; more than 400,000 people.
2. Is there a specific IBD unit in your hospital? Yes; No.

3. How many patients are cared for daily in your unit?

Fewer than 10; between 11 and 20; between 21 and 30; more than 31 .

4. How many patients should be cared for daily? Fewer than 10; between 11 and 20; between 21 and 30; more than 31 .

5. How many days a week are patients seen in these units? $1 ; 2 ; 3 ; 4 ; 5$.

6. How many days a week should patients be seen? $1 ; 2 ; 3 ; 4 ; 5$.

7. How many doctors are there attending this unit? $1 ; 2 ; 3 ; 4$.

8. How many doctors should there be attending this unit?

$1 ; 2 ; 3 ; 4$.

9. Do you have healthcare assistants of your own? No; Yes.

10. Do you think your unit should have their own healthcare assistants?

No; Yes.

11. Does your unit have emergency care?

Yes; No.

12. Do you think your unit should have emergency care? Yes; No.

13. Is there an available telephone hotline for patient care?

No; Yes.

14. Do you think there should be a telephone hotline for patient care?

No; Yes.

15. Are there any day care units in your hospital? Yes; No.

16. Do you think there should be day care units in your hospital?

No; Yes.

17. Is your unit computerized? Yes; No.

18. Do you think it should be? Yes; No.

19. Is your unit provided with patient records? No; Yes.

20. Do you think your unit should have patient records?

No; Yes.

21. Are any clinical trials carried out? No; Yes.

22. Do you think there should be clinical trials performed? No; Yes.

23. Are new treatments easily available? Yes; No.

24. Dou you think they should be? Yes; No. 


\section{RESULTS}

1. How many users does your unit cover? Answer: 6 hospitals (54.5\%) cover a population with more than 400,000 people; and 5 hospitals cover between 250,000 and 400,000 .

2. Is there a specific IBD unit in your hospital? Answer: all hospitals have an IBD unit.

3. How many patients are cared for daily in your unit?

Answer: 5 hospitals (45.4\%) care for between 21 and 30; and 6 hospitals for between 11 and 20 .

4. How many patients should be daily cared for? Answer: ten hospitals (90.9\%) think that between 11 and 20 patients; and one hospital thinks that fewer than 10 .

5. How many days a week are visits scheduled in the IBD unit?

Answer: in 3 hospitals (27.3\%), visits are scheduled once a week; in 4 hospitals (36.4\%) 3 days a week; in 1 hospital 4 days a week; and in 3 hospitals $(27.3 \%) 5$ days a week.

6. How many days a week should they be scheduled? Answer: three hospitals (27.3\%) consider that they should be scheduled twice a week; 3 hospitals that 3 days a week; 2 hospitals consider that 4 days a week; and 3 hospitals consider that 5 days a week.

7. How many doctors are there attending this unit? Answer: in 5 hospitals (45.4\%) only one doctor is attending the unit; in 4 hospitals (36.4\%) two doctors attend the unit; and in 2 hospitals three doctors attend the unit.

8. How many doctors should there be attending this unit?

Answer: five hospitals (45.4\%) consider that there should be 2 doctors attending the unit; four hospitals $(36.4 \%)$ think that 3 doctors; and 2 hospitals $(18.2 \%)$ think that more than 3 doctors.

9. Do you have healthcare assistants of your own? Answer: three hospitals (27.3\%) have their own healthcare assistants; and 8 hospitals (72.7\%) do not have them.

10. Do you think your unit should have healthcare assistants of its own?

Answer: ten hospitals (90.9\%) think that they should; and one hospital think that they should not.

11. Does your unit have emergency care?

Answer: nine hospitals $(81.8 \%)$ have emergency care; and 2 hospitals have no emergency care.

12. Do you think your unit should have emergency care?

Answer: ten hospitals (90.9\%) think that emergency care should be included; and one hospital considers it should be not included.

13. Is there an available telephone hotline for patient care?
Answer: in 5 hospitals (45.4\%) it is not available; and in 6 hospitals it is.

14. Do you think there should be a telephone hotline for patient attendance?

Answer: two hospitals do not consider it necessary; and 9 hospitals $(81.8 \%)$ do consider it necessary.

15. Are there day care units in your hospital?

Answer: there are day care units in every hospital.

16. Do you think there should be day care units in your hospital?

Answer: every hospital thinks that there should be one.

17. Is your unit computerized?

Answer: in five hospitals (45.5\%) units are not computerized; and 6 have computerized units.

18. Do you think it should be?

Answer: all hospitals think that they should be computerized.

19. Is your unit provided with patient records?

Answer: four hospitals $(36.4 \%)$ are not provided with patient records; and 7 hospitals $(63.6 \%)$ do have them.

20. Do you think your unit should have patient records?

Answer: all hospitals think that there should be patient records available.

21. Are any clinical trials carried out?

Answer: none in 2 hospitals, yes in 9 hospitals $(81.8 \%)$.

22. Do you think they should be done?

Answer: two hospitals (18.2\%) think that clinical trials should not be done; and 9 hospitals think that they should.

23. Are new treatments easily available?

Answer: all hospitals have an easy access to new treatments.

24. Dou you think they should be?

Answer: all hospitals think that they should be.

\section{DISCUSSION}

A specific IBD unit is one exclusively dedicated to evaluate, monitor, and treat patients affected by this pathology. Over the last years, the presence of these units has become essential, not only due to the rising incidence and prevalence of IBD, and to the appearance of new treatment options, but also to the low associated mortality, as it has become a chronic disease. Otherwise, easy access for patients to information regarding IBD, such as the Internet, generates a need for attending physicians to be continuously updated (12).

This survey was done following a workflow similar to that of previously published studies carried out by this Group $(10,11)$. One of the main aims was to know if IBD units were present in Andalusian hospitals and their daily 
job development. In the first place, we must point out that this survey has been answered by third-level hospitals, except Hospital de Jerez (Cádiz). This implies a bias in patient selection as only hospitals covering more than 250,000 people were included, which, due to a higher number of patients with IBD, increases the demand for these units. Nevertheless, it is worth noting that all surveyed hospitals count on these units, with more than 11 patients in each office. According to the received answers, seeing more than 20 patients turns out to be quite excessive owing to their complexity and, overall, to the intended use of these units in making scheduled visits compatible with emergency patients. In most of the studied hospitals these units are attended more than twice a week, which is in agreement with the general opinion that they should be attended at least twice a week, depending on demand. In each unit, visits are attended by one or two doctors, although most hospitals consider necessary the presence of at least two doctors. It is important to point out that most of these units do not have healthcare assistants of their own, which makes the correct management of these patients a difficult issue. It has been observed that the presence of a specialized nurse increases effectiveness (13), reducing visits to hospital by up to $38 \%$, increasing patients in remission, and enhancing the quality of life of attended patients.

Doubtlessly, an important matter in a specific IBD unit is seeing emergency patients, which is done in most hospitals. According to Casellas et al. (14), 79.6\% of patients have visited at least once the ER, and $38 \%$ of these visits could have been avoided with a better understanding of the disease or telephonic consultation. This reinforces the utility and need of a specific unit that may offer the possibility of attending emergency patients either in person or via a dedicated telephone number (15). Adequate knowledge of this pathology by patients and scheduled visits increase quality of life and reduce costs derived from this disease as well (16). The usual fixed appointment system rarely provides coincidence of attendance and disease relapse, adverse events derived from drugs, and so on. Another important issue in the correct management of these units is a high level of doctor-patient relationship, providing information over the telephone or directly in the unit, and allowing these patients to perfectly understand the disease including self-medication $(17,18)$.

In all studied hospitals there is a day care unit, which is necessary for certain treatments. However, there is much more heterogeneity regarding other resources such as unit computerization or the presence of patient records, and it is unquestionable that clinical trials and extended access to new treatments are critical for the correct management of patients, especially the most complex ones.

Cooperation with other medical specialists has not been included in this survey, although IBD units must be supported by an interdisciplinary group. According to the white paper on IBD, by 2010 IBD units will be attended by different medical specialists including rheumatolo- gists, ophthalmologists, hematologists, etc., to establish rapid and effective clinical practice. Interconsultation and clinical sessions carried out in conjunction with other medical specialists are also essential. Among other functions, it is also remarkable that these units may be useful to achieve adequate relationships with patient associations or the GETECCU group, and to improve information spread and teaching about this disease.

After analyzing the results obtained, an IBD specific unit seems to be necessary in every hospital with a general Gastroenterology Unit. In these units, patients should be seen at least twice a week, no fewer than 2 doctors should be attending visits, healthcare assistants should be qualified and work exclusively in the unit, a telephone hotline should be available for non-visiting patients, and these units should be capable of attending emergencies without interrupting their daily work. In the same manner, computerized units provided with patient records and the ability to access new treatments and clinical trials are necessary to consider IBD units complete.

The main aim of this unit is to achieve complete management, including follow-up and treatment response monitoring, for patients with IBD as well as an appropriate doctor-patient relationship. It is important that these units are manned not only by gastroenterologists, but also by other medical specialists such as surgeons, rheumatologists, dermatologists, ophthalmologists, and hematologists to dynamize consultations and facilitate periodical clinical sessions in order to make correct decisions.

We concluded that, in Andalusia, specific IBD units are present in most hospitals. These units have become essential due to their functionality, the need for a proper doctor-patient relationship, and their role in reducing direct and indirect public health costs.

\section{REFERENCES}

1. Loftus EV Jr. Clinical epidemiology of inflammatory bowel disease: Incidence, prevalence, and environmental influences. Gastroenterology 2004; 126: 1504-17.

2. Loftus EV Jr, Silverstein MD, Sandborn WJ, Tremaine WJ, Harmsen WS, Zinsmeister AR. Crohn's disease in Olmsted County, Minnesota, 1940-1993: incidence, prevalence, and survival. Gastroenterology 1998; $114: 1161-8$.

3. Loftus EV Jr, Silverstein MD, Sandborn WJ, Tremaine WJ, Harmsen WS, Zinsmeister AR. Ulcerative colitis in Olmsted County, Minnesota, 1940-1993: incidence, prevalence, and survival. Gut 2000; 46: 336-43.

4. Bernstein CN, Blanchard JF, Rawsthorne P, Wajda A. Epidemiology of Crohn's disease and ulcerative colitis in a central Canadian province: a population-based study. Am J Epidemiol 1999; 149: 91624.

5. Pajares JM, Gisbert JP. Epidemiology of inflammatory bowel disease in Spain. A systematic review. Rev Esp Enferm Dig 2001; 93: 9-20.

6. Saro Gismera C, Riestra Menéndez S, Sánchez Fernández R, Milla Crespo A, Lacort Fernández M, Argüelles Fernández G, et al. Epidemiology in inflammatory bowel disease in five areas of Asturias. Spain. An Med Interna 2003; 20(5): 232-8.

7. Garrido A, Martínez MJ, Ortega JA, Lobato A, Rodríguez MJ, Guerrero FJ. Epidemiology of chronic inflammatory bowel disease in the Northern area of Huelva. Rev Esp Enferm Dig 2004; 96(10): 687-91; 691-4. 
8. Estudio Prospectivo Delphi. Costes Sociales y Económicos de la Enfermedad Inflamatoria Intestinal (EII). Faes Farma (eds.) 2005.

9. Kennedy A, Robinson A, Nelson E, Rogers A, Reeves D, Sculpher $\mathrm{M}$, et al. A randomised controlled trial to assess the impact of a package comprising a patient-orientated, evidence-based self-help guidebook and patient-centred consultations on disease management and satisfaction in inflammatory bowel disease. Health Technology Assessment 2003; 7(28).

10. Herrerías Gutiérrez JM, Argüelles Arias F, Martín Herrera L, Montero Domínguez JM, de Dios Vega J, Martín-Vivaldi Martínez R, et al. A high-resolution gastroenterology clinic in Andalusia: what is it, and how should it work. Rev Esp Enferm Dig 2008; 100(1): 5-10.

11. Herrerías Gutiérrez JM, Argüelles Arias F; Andalusian Team of Chiefs of Gastroenterology Units and Departments. Results of a survey in Andalusian endoscopy units. Rev Esp Enferm Dig 2006; 98(12): 929-48.

12. Panés J, Lacy AM, Sans M, Soriano A, Piqué JM. Elevado índice de consultas por internet de los pacientes catalanes con enfermedad inflamatoria intestinal. Gastroenterol Hepatol 2001; 25: 306-9.
13. Nightingale AJ, Middleton W, Middleton SJ, Hunter JO. Evaluation of the effectiveness of a specialist nurse in the management of inflammatory bowel disease (IBD). Eur J Gastroenterol Hepatol. 2000; 12(9): 967-73.

14. Casellas F, Fontanet G, Borruel N, Malagelada JR. The opinion of patients with inflammatory bowel disease on healthcare received. Rev Esp Enferm Dig 2004; 96(3): 174-84.

15. Miller L, Caton S, Lynch D. Telephone clinic improves quality of follow-up care for chronic bowel disease. Nurs Times 2002; 98: 36-8.

16. Kennedy AP, Nelson E, Reeves D, Richardson, Roberts, Robinson $\mathrm{A}$, et al. A randomised controlled trial to assess the effectiveness and cost of a patient orientated self management approach to chronic inflammatory bowel disease. Gut 2004; 53: 1639-45.

17. Robinson A, Thompson DG, Wilkin D, Roberts C. Guided self-management and patient-directed follow-up of ulcerative colitis: a randomised trial. Lancet 2001; 358: 976-81.

18. Saibil F, Lai E, Hayward A, Yip J, Gilbert C. Self-management for people with inflammatory bowel disease. Can J Gastroenterol 2008; 22(3): 281-7. 